University of Wollongong

Research Online

Faculty of Social Sciences - Papers (Archive) Faculty of Arts, Social Sciences \& Humanities

2013

A pilot test of transformational leadership training for sports coaches: Impact on the developmental experiences of adolescent athletes

Stewart A. Vella

University of Wollongong, stvella@uow.edu.au

Lindsay G. Oades

University of Wollongong, loades@uow.edu.au

Trevor P. Crowe

University of Wollongong, tcrowe@uow.edu.au

Follow this and additional works at: https://ro.uow.edu.au/sspapers

Part of the Education Commons, and the Social and Behavioral Sciences Commons

Research Online is the open access institutional repository for the University of Wollongong. For further information contact the UOW Library: research-pubs@uow.edu.au 


\title{
A pilot test of transformational leadership training for sports coaches: Impact on the developmental experiences of adolescent athletes
}

\author{
Abstract \\ This study investigated the impact of a transformational leadership training program for youth sport \\ coaches on adolescent athletes' perceptions of transformational leadership and positive developmental \\ experiences. The transformational leadership training program was associated with higher rates of \\ perceived transformational leadership behaviour at follow-up when compared to baseline measures. \\ Importantly, these increases were associated with significantly higher rates of self-reported \\ developmental experiences. Coach training was associated with a predictability and reliability to athlete \\ outcomes that was not evident in athletes of a comparison group. Transformational leadership may \\ provide a theoretically sound foundation for coaching practice and education in the service of facilitating \\ positive developmental outcomes for athletes.
}

\section{Keywords}

coaches, athletes, impact, developmental, pilot, experiences, test, transformational, leadership, training, sports, adolescent

\section{Disciplines \\ Education I Social and Behavioral Sciences}

\section{Publication Details}

Vella, S. A., Oades, L. G. \& Crowe, T. P. (2013). A pilot test of transformational leadership training for sports coaches: Impact on the developmental experiences of adolescent athletes. International Journal of Sports Science and Coaching, 8 (3), 513-530. 


\title{
A Pilot Test of Transformational Leadership Training for Sports Coaches: Impact on
} the Developmental Experiences of Adolescent Athletes.

\author{
Stewart A. Vella ${ }^{1}$, Lindsay G. Oades ${ }^{2}$, \& Trevor P. Crowe ${ }^{3}$
}

${ }^{1}$ School of Psychology, University of Wollongong, Northfields Avenue, Wollongong, NSW, Australia, 2522.stvella@uow.edu.au

${ }^{2}$ Sydney Business School, University of Wollongong, Innovation Campus, North Wollongong, NSW, Australia, 2522. loades@uow.edu.au

${ }^{3}$ School of Psychology and Illawarra Institute for Mental Health, University of Wollongong, Northfields Avenue, Wollongong, NSW, Australia, 2522. tcrowe@uow.edu.au

Corresponding Author: Stewart A. Vella (stvella@uow.edu.au)

Date of Submission: 20/08/2012 


\begin{abstract}
This study investigated the impact of a transformational leadership training program for youth sport coaches on adolescent athletes' perceptions of transformational leadership and positive developmental experiences. The transformational leadership training program was associated with higher rates of perceived transformational leadership behaviour at follow up when compared to baseline measures. Importantly, these increases were associated with significantly higher rates of self-reported developmental experiences. Coach training was associated with a predictability and reliability to athlete outcomes that was not evident in athletes of a comparison group. Transformational leadership may provide a theoretically sound foundation for coaching practice and education in the service of facilitating positive developmental outcomes for athletes.
\end{abstract}




\section{INTRODUCTION}

Positive youth development is "a field of research and an arena of practice” that has at its core the promotion of growth and resilience in young people [1]. The central tenets of the field include a focus on the potentialities of young people [2], with the aim to equip them with internal and external "assets" that promote an upward developmental trajectory. Internal assets include a commitment to learning, positive values, social competencies and a positive identity. External assets include social support, empowerment, clear boundaries and expectations, and constructive use of time [1]. In order to facilitate upward developmental trajectories, it is generally agreed that youth must be embedded in multiple relationships, contexts and human systems that nurture their growth [1].

Larson [3] argues that sustained positive youth development best occurs within the often complex, messy and disordered realities of the real world. This is because young people need agency in order to fulfil their potential. Agency is the "abilities to organise and regulate actions over time to work toward a long term goal, as an individual or with others, in complex real world contexts (pg. 318) [3].” In order to do this young people need a range of skills such as cognitive skills, the ability to regulate emotions, and continued motivation. These abilities are both hindered and developed by the positive and negative interpersonal interactions that are a normal part of human systems [3]. Within the sports domain, recent research shows that the strongest influence on the developmental outcomes of youth sports participation is the interaction with significant others involved in the sport [4].

Youth sports participation has been shown to correlate with many developmental assets in youth, including physical, cognitive and social competencies [5]. In addition, participation in youth sports has been associated with a healthy self-esteem, higher rates of pro-social engagement and academic achievement, and the development of character and life skills [6-8]. According to Weiss [8], sport provides a set of naturally occurring opportunities 
of which adult leaders may use to facilitate the acquisition of developmental assets. Vella et al. [9] have also inferred that both "winning" and "losing” in youth sports provide an opportunity for developmental gains to be promoted by the coach.

The relationship between the coach and athlete is seen as one of the most important determinants of the effects of youth sports participation [10-11]. Many conceptualisations of coaching have specified the positive psychological and social growth of young athletes as basic elements of effective practice [7-8]. This is reinforced by the definition of coaching effectiveness as facilitating increases in key developmental areas including self-esteem, physical activity, interpersonal networks and moral decision making [12]. This definition has been based on a wider review of the athlete development literature which has demonstrated that athlete development can occur across four major areas known as the "4 Cs": competence; confidence; connection, and; character/caring. This conceptualisation of athlete development has been drawn directly from a conceptualisation of positive youth development known as the " 5 Cs" (the 5 Cs separate character and caring into two separate domains) [13], and reflects the basic groupings of outcomes that may potentially be derived from sports participation. These outcomes broadly encapsulate basic skills and competencies, self-esteem and self-confidence, positive interpersonal connections, and pro-social behaviours. In addition, coaching practitioners maintain positive youth development as an overarching aim of their coaching practice, and see themselves as responsible for facilitating a wide-ranging set of interrelated positive developmental outcomes such as self-esteem, social skills, life skills and positive affect [14].

Cross-sectional research demonstrates that the positive developmental experiences of young athletes are associated with coaches’ transformational leadership behaviour [9]. In addition, a test of transformational leadership theory amongst adolescent athletes has shown that coach transformational leadership behaviour predicts athlete outcomes at both an 
individual and team level [15]. This is in addition to descriptive research undertaken in both University and adult sporting context which associates coach transformational leadership behaviour with positive athlete outcomes [16-19].Transformational leadership is a form of leadership that occurs when leaders: broaden and enlarge the interest of those whom they lead; act morally; motivate their followers to go beyond individual self-interest for the good of the group and address and engage each individual follower in true commitment [20]. Transformational leadership is comprised of four basic components: idealised influence, where leaders serve as role models for followers, demonstrating high values and positive behaviours; inspirational motivation, where leaders will inspire followers through the development and communication of a vision; intellectual stimulation, where leaders challenge existing assumptions and stimulate thought in followers about how goals may be achieved, and; individual consideration, where leaders individualise behaviours directed at following by meeting the unique personal needs and concerns of followers [20].

In conceptualising transformational leadership within the sporting context, Callow et al. adapted a conceptualisation of transformational leadership to the sporting domain. The authors adapted a measure of transformational leadership from the military setting which included the transformational behaviours of 'fostering acceptance of group goals,' where leaders promote cooperative efforts among followers in order to achieve a common goal, and 'high performance expectations,' where leaders provide positive expectations of all followers. In addition, this conceptualisation included one transactional leadership behaviour, ‘contingent reward,' where leaders provide positive reinforcements that are contingent upon the display of desired behaviours by followers [17]. Transactional leadership is a form of leadership where the compliance by followers is promoting through a system of rewards and punishments. The addition of transactional leadership behaviours to transformational 
leadership behaviours is known as 'full range' leadership [20]. According to this model, contingent reward is the most effective transactional leadership behaviour.

Subsequent work by Vella, Oades and Crowe [21] has conceptualised transformational leadership within a participation youth sports context. Within this context, 'high performance expectations’ was removed as a component of transformational leadership due to theoretical inconsistency with the goals of participation youth sport. Thus, transformational leadership has been conceptualised within this context as incorporating 5 key transformational components, as well as one transactional leadership component:

- Appropriate role modelling is defined as "the extent to which the coach provides a positive behavioural model for athletes to follow.” This should include modelling of all desirable behaviours including pro-social behaviour, equitable treatment of others, respect for the opposition and referee, and goal setting to name just a few.

- Intellectual stimulation is "the extent to which the coach can challenge athletes cognitively.” For example, the coach may challenge athletes to come up with new ways of learning or a new team strategy by asking thought-provoking questions during practice.

- Individual consideration is defined as "the extent to which the coach is able to understand and meet the individual needs for growth and development of each athlete.” This may include an in-depth knowledge of the skill level of each player so that the coach is able to set practice drills at an appropriately challenging level for each individual.

- Inspirational motivation is "the extent to which the coach is able to motivate athletes by providing inspiration and an incentive to perform well.” The essence of this behaviour is that the coach uses a vision of the future to motivate athletes, rather than a simple system of punishment and reward. 
- Fostering acceptance of group goals refers to "the extent to which the coach can facilitate team cohesion.' This should include both social and task cohesion.

- Contingent reward is a transactional leadership behaviour and is defined as "the extent to which the coach uses positive reinforcement to strengthen desired athlete behaviours (p. 212-213) [21].” This system of reinforcement should be used in addition to the transformational leadership behaviours by providing rewards or praise for any desirable or positive behaviour.

The importance of transformational leadership in youth sports has been outlined by Vella et al. [21]. Unique components such as inspirational motivation and intellectual stimulation are important because youth sports are expounded as appropriate avenues for youth development due to simultaneously high levels of attention, motivation and challenge [22]. Further, components such as individual consideration and fostering acceptance of group goals speak to the inherent nature of coaching practice as constituted by the relationship between coach and athlete [23], which itself is set amongst the context of the multiple interpersonal relationships. The importance of these components are highlighted by research that has shown that the personal experience of effective coaching is predominantly about the relationships and environment that the coach creates rather than a limited range of prescribed behaviours [24].

Given that the extent of the literature pertaining to transformational leadership in youth sports is theoretical [21], cross-sectional [9, 15-17] and qualitative [19], there exists a need to extend this research by piloting a transformational leadership intervention for coaches. Using a quasi-experimental design, the purpose of this study is to strengthen the associations made between transformational leadership behaviour and the positive developmental experiences of adolescent athletes by piloting a transformational leadership training program for coaches. The specific aim of the program was to increase coach 
transformational leadership behaviours and gauge the impact on the positive developmental experiences of young athletes. Importantly, the effectiveness of this program was to be judged within "real world" coaching practice that is integral to the sustained development of positive outcomes for young athletes. It was also important to gauge the effectiveness of this pilot program in two key areas. Firstly, does the leadership training program lead to higher rates of perceived transformational leadership behaviour? Secondly, do higher rates of perceived coach transformational leadership behaviour lead to higher rates of positive developmental experiences for athletes? Evidence from Smoll and Smith’s Coach Effectiveness Training shows that a cognitive-behavioural training program for coaches of 75-120 minutes duration can have a significant impact on both the perceptions and outcomes for young athletes [25-27]. Therefore, in order to answer these questions, the leadership training program was administered to all coaches of one youth soccer club, while a second club acted as a naturalistic comparison. Naturalistic inquiry is a paradigm for research which incorporates the comparison of individuals in their "real life", and is thus integral to judging the success of coach training programs at facilitating positive athlete outcomes [28]. Relative to a comparison group, and to baseline measures, it was hypothesised that athletes of coaches who are trained in transformational leadership will: (1) perceive a higher rate of transformational leadership behaviours, and; (2) report a higher rate of positive developmental experiences.

\section{METHOD}

\section{Design}

This study was conducted using a quasi-experimental pre-post design for nonequivalent groups over two complete sporting seasons. A quasi-experiment is a study that takes place in a naturalistic setting where either the random assignment of participants or the controlled manipulation of the independent variable is not possible [29]. In this case, the 
random assignment of participants into sporting clubs is not possible, thus, an intervention targeted at the independent variable (coach leadership) is assigned to the pre-existing groups. The benefit of quasi-experimental research is that it enables the strengthening of causal inferences while maintaining internal and external validity without interrupting 'real life' through intrusive intervention and is therefore the most appropriate form of intervention for this study [29-30]. The coach training program commenced at the conclusion of season one and prior to season two. Baseline measures were taken toward the end of season one and follow-up measures were taken toward the end of season two.

\section{Participants}

Two soccer clubs of near equivalence participated in the study. Clubs were matched on the total number of players at the club (club size), and the spread of players throughout the age groups of relevance, with each club having 9 teams. One club participated as an active group whose coaches took part in the transformational leadership training program (herein referred to as the active group). The remaining club acted as a naturalistic comparison group whose coaches received no training (the comparison group). In season one and two, each club had 9 teams competing over the male and female competitions from the ages of 12 to 18 years. The club participating as the active group had a total of 116 players in these age groups who were registered in both season one and two, while the comparison club had a total of 127 players over both seasons. Players from both clubs attended training with their coach of approximately 1-1.5 hours and trained once per week. Each team competed once per week over the course of 18 weeks. The clubs had a similar spread of playing ability, each with 5 teams in the ' $A$ ' grade, 2 in the ' $\mathrm{B}$ ' grade, and 1 each in ' $C$ ' and ' $\mathrm{D}$ ' grade. The club participating as the active group typically drew players from a higher socioeconomic status area than the comparison group. The comparison group was offered the coach training program following the conclusion of this study. 
Active Group. The active group contained two subsets of participants; players and coaches. Each of the nine coaches of teams from 12 to 18 years of age participated in the transformational leadership training program. Coaches ranged from 25 to 58 years of age with a mean age of 40.67 years $(S D=10.13)$ in season two. All coaches were male and responsible for the same team in season one and two. At baseline, a total of 66 players participated (37 male, 29 female). The average age of players participating at baseline was 14.75 years $(S D=2.02)$. Post intervention, 67 players participated in the study ( 29 males, 38 females), with an average age of 15.78 years $(S D=1.98)$. The anonymous nature of the data collected meant that it was not possible to ascertain how many players (out of the pool of 116 players) completed measures at both pre- and post-intervention.

Comparison Group. As with the active group, all nine coaches in the comparison group were male. The coaches were aged from 23 to 48 years in season two, with a mean age of 41.44 years $(\mathrm{SD}=9.92)$. Only 7 of the 9 coaches were coaching at the comparison club in both season one and two. Baseline measures were taken from 67 players (32 male, 35 female), with a mean age of 14.70 years $(S D=1.64)$. In season two a total of 80 players participated in the study (47 male, 33 female), with an average age of 14.72 years (SD = 2.38). As with the active group, the anonymous nature of the data collected meant that it was not possible to ascertain how many players (out of the pool of 127 players) completed measures at both pre- and post-intervention.

\section{Measures}

Perceived Transformational Leadership Behaviour. The Differentiated Transformational Leadership Inventory for Youth Sport [DTLI-YS; 21] was used to measure players’ perceptions of their coach's transformational leadership behaviours. The DTLI-YS contains 22 items on a 5-point Likert scale. Players are asked to judge how frequently each statement fits their coach's normal behaviour, ranging from 1 (Not at all) to 5 (All of the time). The 
DTLI-YS incorporates six separate subscales of coach behaviour that are consistent with transformational/transactional leadership; individual consideration (4 items), intellectual stimulation (3 items), inspirational motivation (4 items), appropriate role modelling (4 items), fostering acceptance of group goals (3 items), and contingent reward (4 items). Support for this six factor model within a youth sport population is strong [21]. Example items from the DTLI-YS include: 'My coach is a good role model for me to follow'(appropriate role modelling subscale); 'My coach recognises that different athletes have different needs' (individual consideration subscale) and 'My coach gets me to rethink the way that I do things' (intellectual stimulation subscale). Given that the number of items per subscale is not uniform, means for the 'fostering acceptance of group goals' and 'intellectual stimulation' subscales have been corrected for number of items. The DTLI-YS has a strong underlying model fit and internal reliability within this population $\left(\alpha>.75\right.$ for all subscales; $\chi^{2}=372.54$, $\left.p<.001 ; \chi^{2} / d f=1.92 ; \mathrm{CFI}=.96 ; \mathrm{TLI}=.95 ; \mathrm{RMSEA}=.05 ; \mathrm{SRMR}=.04 ;[21]\right)$. Athletes’ Developmental Experiences. Self-reported developmental experiences were measured using the Youth Experience Survey for Sport [YES-S; 31]. The YES-S contains 37 items that assess the extent of acquisition of a range of developmental assets and experiences over five subscales: personal and social skills (14 items); cognitive skills (5 items); goal setting (4 items); initiative (4 items) and negative experiences (10 items). Each item is rated on a 4-point Likert scale from 1 (Not at all) to 4 (Yes definitely). Examples of items from the YES-S are 'I became better at taking feedback' (personal and social skills subscale), 'I set goals for myself in this activity’ (goal setting subscale), 'I learned to push myself' (initiative subscale), and 'This activity has stressed me out' (negative experiences subscale). The YES-S has a strong underlying model fit, and high internal consistency with alpha values above .82 for all subscales [31].

\section{Procedure}


Survey completion. All measures were completed 12 months apart, at the end of season one and two. This allowed each athlete the maximum amount of time with their coach before survey completion. Each club was responsible for contacting all eligible players and coaches. The nominated caregivers for players aged under 16 years were also contacted. Survey completion took place at the club house of the participating clubs during the last two weeks of each season. Each participant and their caregivers were given written and verbal information on the study and consent forms were completed by caregivers of participants under 16 years of age. Tacit consent was given by older participants by returning the completed surveys. The surveys were completed in a quiet environment and took between 10 and 25 minutes to complete. Each participant was assured of anonymity. This was aided by all parents leaving the room for survey completion and the provision of a secure box for the participants to place their completed surveys in.

Coach transformational leadership training program. The coach transformational leadership training program was constituted by one group session of 2 hours duration. This group session was adapted to reflect a transformational leadership approach, using a format based upon the highly successful Coach Effectiveness Training/Mastery Approach to Coaching training program used by Smoll and Smith [32]. This program was used because the format has a relatively large amount of literature to demonstrate its success in facilitating positive developmental outcomes for participants of youth sports [25, 33-34]. This was then followed by monthly follow up telephone calls for the duration of the sporting season. In all, 5 telephone calls were made to each coach who attended the initial group session. The single group session plus follow-up telephone calls format was chosen to limit the time commitments of the participating coaches to a level that was deemed acceptable by the participating club. In addition, this format was used to maximise prolonged motivation, convenience, and impact. The single group session was deemed necessary to facilitate social 
support for the coaches, to transfer a large amount of information with the aid of electronic media, and to facilitate an informed commitment to goals in front of others. Telephone calls were primarily used to ensure continued goal striving by the coaches. A typical telephone conversion followed the GROW (Goals, Reality, Options, What) structure outlined by Wilson [35]. Within this model, conversation proceeds systematically by discussing the goals of the coach, assessing progress towards goals (reality), investigating options and strategies for goal attainment (options), and making commitments to reaching goals (what). The structure, content and purpose of the group session and follow up discussions are given in Table 1. Data Analysis. At the request of the active club, all data collected was to be completed anonymously by athletes so that data on individual coaches was not available. This condition was absolute and non-negotiable. In order to maintain anonymity and to ensure that results for individual coaches were not obtainable, data on team membership was not collected. Thus, multilevel analyses are not possible. Further, anonymity for all athletes meant that it was not possible to follow participants from pre- to post-intervention. Data collected at postintervention was collected from the same pool of participants as pre-intervention, however, the anonymous nature of the data means that it is impossible to know if the same or different athletes completed measures pre- and post-intervention. Accordingly, the data has been analysed as belonging to four separate groups: active group at baseline; comparison group at baseline; active group at follow-up, and; comparison group at follow-up. Missing data from 11 participants (4\%) was replaced using the full information maximum likelihood method of estimation. 
Table 1

The structure, content and purpose of the transformational leadership training program

\begin{tabular}{|c|c|c|}
\hline Component & Purpose & Specific Content \\
\hline $\begin{array}{l}\text { Introduction to initial } \\
\text { session }\end{array}$ & $\begin{array}{l}\text { a. Provide an introduction to the complete program and } \\
\text { outline the coaching program }\end{array}$ & a. Welcome and overview of course \\
\hline $\begin{array}{l}\text { Education: Athlete } \\
\text { Outcomes in Youth } \\
\text { Sport }\end{array}$ & $\begin{array}{l}\text { a. Increase coaches' awareness of important developmental } \\
\text { outcomes of youth sport } \\
\text { b. De-emphasise the importance of winning } \\
\text { c. Facilitate a change in values that drive coach behaviour }\end{array}$ & $\begin{array}{l}\text { a. Presentation of the } 4 \text { Cs (Competence, confidence, connection, } \\
\text { character; Cote \& Gilbert, 2009) as athlete outcomes } \\
\text { b. Discussion about what } 4 \text { Cs look like in practice }\end{array}$ \\
\hline $\begin{array}{l}\text { Education: } \\
\text { Transformational } \\
\text { Leadership }\end{array}$ & $\begin{array}{l}\text { a. Increase coaches' awareness of the importance of } \\
\text { transformational leadership in coaching } \\
\text { b. Educate coaches about the components of } \\
\text { transformational leadership } \\
\text { c. Increase the value that coaches place on transformational } \\
\text { leadership }\end{array}$ & $\begin{array}{l}\text { a. Presentation of the seven transformational leadership } \\
\text { components set out in the DTLI-YS } \\
\text { b. Outline of the links between transformational leadership in } \\
\text { coaching and positive outcomes for athletes }\end{array}$ \\
\hline $\begin{array}{l}\text { Common Scenarios } \\
\text { Workshop }\end{array}$ & $\begin{array}{l}\text { a. Educate coaches about what transformation leadership } \\
\text { looks like in their coaching practice } \\
\text { b. Give coaches some behavioural guidelines when dealing } \\
\text { with commonly faced scenarios } \\
\text { c. Facilitate independent thought about solving common } \\
\text { problems in a 'transformational' way }\end{array}$ & $\begin{array}{l}\text { a. } 6 \text { common scenarios are presented and coaches are asked to } \\
\text { discuss how a transformational leader would handle these } \\
\text { situations (e.g., misbehaving players, facilitating team } \\
\text { cohesion, loss of first game) }\end{array}$ \\
\hline Goal Setting & $\begin{array}{l}\text { a. To set SMART goals according to what they had learnt } \\
\text { about transformational leadership } \\
\text { b. To teach coaches how to set SMART goals }\end{array}$ & $\begin{array}{l}\text { a. Outline of SMART goals } \\
\text { b. Articulate } 3 \text { SMART goals } \\
\text { c. Articulate sub-goals for each SMART goal that will allow } \\
\text { them to attain those goals }\end{array}$ \\
\hline $\begin{array}{l}\text { Facilitating Self- } \\
\text { Awareness }\end{array}$ & $\begin{array}{l}\text { a. Increase the coaches' awareness of their own coaching } \\
\text { behaviours } \\
\text { b. To increase awareness of desired transformational } \\
\text { leadership behaviours }\end{array}$ & $\begin{array}{l}\text { a. Self-report version of the DTLI-YS } \\
\text { b. Encouragement to seek feedback from parents and athletes }\end{array}$ \\
\hline Training Manual & $\begin{array}{l}\text { a. Allow coaches to contribute during session } \\
\text { b. Give coaches outline of session and material to reference } \\
\text { during season }\end{array}$ & $\begin{array}{l}\text { a. Detailed outline of all content covered in session } \\
\text { b. Avenues for further information } \\
\text { c. Contact numbers for help if needed }\end{array}$ \\
\hline $\begin{array}{l}\text { Individual Monthly } \\
\text { Follow-Ups }\end{array}$ & $\begin{array}{l}\text { a. Check on goal striving and attainment } \\
\text { b. Maintain awareness and motivation } \\
\text { c. Provide practical assistance } \\
\text { d. Provide additional coaching and mentoring } \\
\text { e. Individualise programs for coaches }\end{array}$ & a. Telephone conversations between researcher and youth coach \\
\hline
\end{tabular}




\section{RESULTS}

\section{Descriptive statistics}

The aggregated data were subjected to tests of normality and heterogeneity of variance. Data from the DTLI-YS had a moderate negative skew and moderate kurtosis values. In particular, the individual consideration subscale (skewness $=-1.28$, kurtosis $=2.23$ ), inspirational motivation subscale (skewness $=-1.29$, kurtosis $=2.74$ ), fostering acceptance of group goals subscale (skewness $=-1.12$, kurtosis $=1.06$ ), and contingent reward subscale (skewness $=$ 1.12, kurtosis $=1.03)$. All data from these scales were transformed using the squared transformation as described by Tabachnick and Fidell [36] for moderately negatively skewed data. Following this transformation, data proved to be normally distributed (Skewness statistics ranging from -.10 to -.71, and Kurtosis statistics ranging from .02 to -.30). Analyses were subsequently conducted using the transformed data. All YES-S data were normally distributed and were not transformed. The internal consistency of all scales and subscales was good with Cronbach’s Alpha values of above .70. All Cronbach’s Alpha coefficients are given in Table 2. The mean subscale scores and standard deviations of the active and comparison groups by season are also given in Table 2. For ease of interpretation the untransformed statistics are given. A summary of differences is also given in Table 3. 
Table 2

Mean responses and standard deviations for the DTLI-YS and YES-S by Group and Time

\begin{tabular}{|c|c|c|c|c|c|c|c|c|c|}
\hline & \multirow[b]{3}{*}{$\alpha$} & \multicolumn{4}{|c|}{ Season 1} & \multicolumn{4}{|c|}{ Season 2} \\
\hline & & \multicolumn{2}{|c|}{ Active Group } & \multicolumn{2}{|c|}{$\begin{array}{l}\text { Comparison } \\
\text { Group }\end{array}$} & \multicolumn{2}{|c|}{ Active Group } & \multicolumn{2}{|c|}{$\begin{array}{l}\text { Comparison } \\
\text { Group }\end{array}$} \\
\hline & & $M$ & SD & $M$ & SD & $M$ & SD & $M$ & SD \\
\hline Individual Consideration & .76 & 16.58 & 3.49 & 16.15 & 2.83 & 17.57 & 2.06 & 16.27 & 3.18 \\
\hline Inspirational Motivation & .77 & 16.76 & 2.71 & 16.46 & 2.57 & 17.61 & 1.94 & 16.52 & 3.31 \\
\hline Intellectual Stimulation & .74 & 10.94 & 2.12 & 11.06 & 2.73 & 12.31 & 1.99 & 11.07 & 2.94 \\
\hline Contingent Reward & .82 & 16.42 & 3.02 & 16.87 & 2.73 & 17.95 & 1.99 & 17.05 & 3.03 \\
\hline DTLI-YS Total & .94 & 89.14 & 12.79 & 87.94 & 12.71 & 96.10 & 9.74 & 88.52 & 17.24 \\
\hline \multicolumn{10}{|l|}{ YES-S } \\
\hline Personal and Social Skills & .77 & 42.95 & 6.69 & 44.04 & 5.33 & 44.94 & 8.73 & 40.50 & 8.36 \\
\hline Cognitive Skills & .85 & 8.70 & 3.18 & 4.49 & 3.85 & 11.57 & 4.03 & 11.40 & 4.37 \\
\hline
\end{tabular}

Note. Higher scores represent perceptions of higher rates of transformational leadership behaviour, and a greater number of reported developmental experiences. In the case of negative experiences, higher scores represent a greater number of negative experiences.

\section{Hypothesis 1: Transformational Leadership Behaviour}

Hypothesis one states that athletes of coaches who received transformational leadership training will perceive a higher rate of coach transformational leadership behaviours relative to baseline measures and a comparison group. In order to investigate potential differences in perceived transformational leadership behaviours as a result of the training intervention all measures were subjected to a multivariate analysis of variance (MANOVA). Each of the DTLI subscales, as well as an overall measure, were entered as dependent variables. A Bonferroni adjustment was made to the alpha level in order to reflect the 6 concurrent comparisons. Hence, the adjusted alpha level required for significance was .007. The MANOVA revealed significant differences between at least two of the groups on at least one measure of transformational leadership behaviour $(\Lambda=.863, p=.002)$. Tests of between subjects effects showed that there were significant differences between groups on levels of appropriate role modelling $(F=6.01, p=.001)$, fostering acceptance of group goals $(F=$ 5.20, $p=.002)$, intellectual stimulation $(F=5.03, p=.002)$, and overall transformational 
leadership behaviour $(F=6.03, p=.001)$. There were no differences between any of the groups on levels of individual consideration, inspirational motivation, and contingent reward $(p>$.007). Post-hoc Bonferroni comparisons were used to analyse where these differences occurred. Corresponding adjustments to alpha levels were made and significant difference is reflected at an alpha level of .05. A summary of differences can be found in Table 3. Appropriate Role Modelling. Post-hoc Bonferroni comparisons showed significant differences in levels of appropriate role modelling between baseline and follow-up measures in the active group. Thus, athletes of trained coaches reported significantly higher rates of appropriate role modelling at follow-up than at baseline $(p=.029)$, and compared to the comparison group at follow-up $(p=.002)$. There was no difference in levels of appropriate role modelling reported by athletes in the comparison group at baseline and follow-up ( $p>$ $.05)$.

Fostering Acceptance of Group Goals. Post-hoc Bonferroni comparisons showed that athletes of trained coaches reported higher means than athletes in the comparison group at follow-up $(p=.004)$. There was no difference in the extent to which coaches in the active or comparison groups were reported to have fostered acceptance of group goals at baseline and follow-up $(p>.05)$.

Intellectual Stimulation. Post-hoc Bonferroni comparisons showed significant differences in reported levels of intellectual stimulation. Athletes of trained coaches reported significantly higher rates of intellectual stimulation behaviours at follow-up when compared to baseline ( $p$ $=.007)$. Further, athletes of trained coaches reported higher levels of intellectual stimulation at follow-up when compared with the comparison group $(p=.009)$. There was no difference between baseline and follow-up measures in the comparison group $(p>.05)$.

Overall Measure of Transformational Leadership Behaviour. Post-hoc Bonferroni comparisons showed a significantly higher rate of overall transformational leadership 
behaviour for trained coaches at follow-up when compared to baseline $(p=.013)$. A significant difference between the active and comparison groups shows that athletes of trained coaches reported higher levels of overall levels of transformational leadership behaviour than athletes in the comparison group at follow-up $(p=.002)$. There was no difference in levels of transformational leadership behaviour reported by athletes in the comparison group at baseline and follow-up ( $p>.05)$.

\section{Hypothesis 2}

Hypothesis two states that athletes of coaches trained in transformational leadership will report higher rates of positive developmental experiences at follow-up than at baseline, as

well as higher rates of positive developmental experiences than a comparison group. In order to investigate potential changes in positive developmental experiences as a result of the training intervention all measures were once again subjected to a MANOVA. Each of the YES-S subscales, as well as an overall measure, were entered as dependent variables. A Bonferroni adjustment was made to the alpha level in order to reflect the 6 concurrent comparisons. Hence, the adjusted alpha level required for significance was .007. A MANOVA revealed significant differences between at least two of the groups on at least one measure of developmental experiences $(\Lambda=.718, p<.001)$. Tests of between subjects effects showed that there were significant differences between groups on levels of: personal and social skills $(F=5.17, p=.002)$; cognitive skills $(F=9.06, p<.001)$; goal setting $(F=8.62$, $p<.001)$; initiative $(F=14.95, p<.001)$ and an overall measure of developmental experiences $(F=7.36, p<.001)$. There were no differences between any of the groups on levels of negative experiences ( $p>$.007). Post-hoc Bonferroni comparisons were used to analyse the specific differences between individual groups. Once again, corresponding adjustments to alpha levels were made and significant difference is reflected at an alpha level of .05. A summary of differences can be found in Table 3. 
Personal and Social Skills. Post-hoc Bonferroni comparisons showed no difference in personal and social skill experiences for athletes of trained coaches between baseline and follow-up groups $(p>.05)$. However, levels of personal and social skill experiences were significantly higher for athletes in the active group than athletes in the comparison group at follow-up $(p=.002)$. Correspondingly, athletes in the comparison group reported significantly fewer personal and social skill experiences at follow-up than at baseline $(p=$ $.019)$.

Cognitive Skills. Bonferroni comparisons showed a significantly higher rate of cognitive skill experiences reported by athletes in the active group at follow-up when compared to baseline $(p=.019)$. Similarly, athletes in the comparison group also reported a significantly higher rate of cognitive skill experiences at follow-up when compared to baseline $(p=.032)$. There was no difference in the levels of cognitive skill experiences reported by athletes in the active group and comparison group at follow-up $(p=.032)$.

Goal Setting. Post-hoc Bonferroni comparisons showed a significantly higher rate of goal setting experiences reported by athletes in the active group at follow-up compared to baseline $(p=.009)$. Athletes in the comparison group reported a significantly lower rate of goal setting experiences at follow-up compared to baseline $(p=.035)$. Levels of goal setting experiences were significantly higher for athletes in the active group than athletes in the comparison group at follow-up $(p<.001)$.

Initiative. Bonferroni comparisons showed no difference in the initiative experiences reported by athletes in the active group at baseline and follow-up ( $p>.05)$. However, athletes in the comparison group reported significantly lower rates of initiative experiences at follow-up compared to baseline $(p<.001)$. Consequently, levels of initiative experiences were significantly higher for athletes in the active group than athletes in the comparison group at follow-up $(p<.001)$. 


\section{Overall Measure of Positive Developmental Experiences. Post-hoc Bonferroni}

comparisons showed no difference in the overall levels of reported positive developmental experiences for athletes in the active group between baseline and follow-up $(p>.05)$. A significant difference between the active and comparison groups at follow-up shows that athletes of trained coaches reported higher levels of overall positive developmental experiences than athletes in the comparison group $(p<.001)$. Athletes in the comparison group reported significantly fewer positive developmental experiences at follow-up compared to baseline ( $p=.016)$. Athletes of trained coaches reported a higher level of overall positive developmental experiences than athletes in the comparison group at follow-up $(p<.001)$.

Table 3

Summary of differences between the four groups under study by construct.

\begin{tabular}{|c|c|c|c|c|}
\hline Construct & $\begin{array}{c}\text { Differences between } \\
\text { AG and CG at BL }\end{array}$ & $\begin{array}{c}\text { AG: Differences } \\
\text { between BL and FU }\end{array}$ & $\begin{array}{c}\text { CG: Differences } \\
\text { between BL and FU }\end{array}$ & $\begin{array}{c}\text { Differences between } \\
\text { AG and CG at FU }\end{array}$ \\
\hline \multicolumn{5}{|l|}{ DTLI-YS } \\
\hline Individual Consideration & - & - & - & - \\
\hline Inspirational Motivation & - & - & - & - \\
\hline Intellectual Stimulation & - & Higher at FU & - & AG higher \\
\hline Fostering Group Goals & - & - & - & AG higher \\
\hline Appropriate Role Modelling & - & Higher at FU & - & AG higher \\
\hline Contingent Reward & - & - & - & - \\
\hline DTLI-YS Total & - & Higher at FU & - & AG higher \\
\hline \multicolumn{5}{|l|}{ YES-S } \\
\hline Personal and Social Skills & - & - & Lower at FU & AG higher \\
\hline Cognitive Skills & - & Higher at FU & Higher at FU & - \\
\hline Goal Setting & - & Higher at FU & Lower at FU & AG higher \\
\hline Initiative & - & - & Lower at FU & AG higher \\
\hline Negative Experiences & - & - & - & - \\
\hline YES-S Total & - & - & Lower at FU & AG higher \\
\hline
\end{tabular}

Note. $\mathrm{AG}=$ Active group. $\mathrm{CG}=$ Comparison group. $\mathrm{BL}=$ Baseline. $\mathrm{FU}=$ Follow-up.

\section{DISCUSSION}

The purpose of this study was to gauge the impact of a transformational leadership training program for youth sport coaches on coach transformational leadership behaviours, and the positive developmental experiences of adolescent athletes. The first hypothesis was that athletes of coaches who received transformational leadership training would perceive higher rates of transformational leadership behaviour following training and higher rates than athletes from the comparison group. This hypothesis was partially supported. Trained 
coaches were perceived to exhibit higher rates of transformational leadership behaviours at follow-up when compared to baseline. Interestingly, higher rates were reported in two components of transformational leadership, namely intellectual stimulation and appropriate role modelling, as well as an overall measure of transformational leadership behaviour. Each of these was also reported at significantly higher levels than the comparison group postintervention. This may be because coaches of youth sports are, in general, not as cognisant of these responsibilities during their coaching practice as they are of the remaining transformational leadership behaviours such as the use of rewards or facilitating the acceptance of team goals.

Hypothesis two was that higher rates of coach transformational leadership behaviours would be associated with higher rates of positive developmental experiences for athletes. This hypothesis was also partially supported. Two of the five components of the developmental experiences measure realised higher rates at follow-up when compared to baseline measures. These were cognitive skill and goal setting experiences. The increase in cognitive skill experiences is particularly interesting given the corresponding increase in the perceived level of coaches' intellectual stimulation. Increases in goal setting may have been reported because of a relatively heavy influence on goal setting during the coach training program. The parallel process evident in coach education theorises that coaches will acquire a set of behavioural skills that are consistent with those that are demonstrated by coach educators [37]. However, in order to enhance the understanding of these results they need to be seen in the light of results from the comparison group. The comparison group reported fewer positive developmental experiences at follow-up when compared to baseline. This was constituted by fewer experiences related to personal and social skills, goal setting, and initiative. 
These results shed some light on the area of positive youth development through sport. Until now, very little has been known about the causal mechanisms that explain the variability in developmental outcomes that are garnered by young athletes as a result of sports participation. In particular, little is known about specific qualities and behaviours of the coach that may impact these outcomes [38]. Consequently, this lack of evidence is manifested in an inability to increase the consistency of systematic developmental benefits [39]. This study has attempted to strengthen associations made between transformational leadership and positive youth development through sport. Due to the limitations of this study, causal inferences cannot be made. However, following training in transformational leadership, coaches were perceived to have exhibited higher rates of transformational leadership behaviour, and this corresponded with a higher rate of reported positive developmental experiences.

It appears that training program given to coaches increased the reliability and predictability of systematic positive developmental experiences. Athletes of trained coaches reported at worst no difference in developmental experiences and at best reported significantly higher rates at follow-up. This was associated with higher rates of perceived transformational leadership behaviours. In contrast, the developmental outcomes for athletes of untrained coaches were highly variable and, for some constructs, poorer than those for athletes of trained coaches. This provides some evidence for a strengthening of the association between coach leadership, coach education, and positive outcomes for young athletes. This is consistent with previous work in this area [40]. It also serves to verify that there is nothing inherent in sport that guarantees positive developmental outcomes for athletes. Rather, appropriately trained coaches are more likely to take advantage of naturally occurring 'teaching moments' [8]. This study suggests that where coaches are not appropriately trained, developmental outcomes for athletes can be highly varied and, at times, 
more negative. Training that equips coaches with developmentally appropriate knowledge and skills may not guarantee positive youth development, but it will go some way to equipping coaches with the ability to facilitate positive developmental outcomes for athletes. Coach training may be an important program for positive youth development. Conroy and Coatsworth [39] promote coach training as a powerful and cost effective solution to promoting positive youth development through sport. This is predicated on the basis that coaches hold a position of influence and are seen as an expert and role model by young participants. Coaches also have a greater number of interactions within the sporting context than other influential agents such as parents or policy makers. Coach training programs have been shown to lead to increases in athlete self-esteem [27, 34], as well as personal and social skills [40]. However, mainstream coach education programs lack content that is relevant to positive youth development, instead maintaining a focus on technical and tactical skills. This leaves coaching practitioners ill equipped to develop consistent and meaningful developmental gains for young athletes [41]. It may be for this reason that coaches of young athletes see mainstream coach education programs as somewhat irrelevant, and therefore are reluctant to engage in further coach education. They would be more likely to do so following the inclusion of more relevant topics such as communication skills, motivation and building character [42].

Transformational leadership is one potential addition to coach training programs. Indeed, coach education based on a coherent and consistent theoretical approach with demonstrated efficacy is a considerable and substantial need [39]. Transformational leadership can provide a theoretically sound, empirically validated foundation for coaching practice and education in the service of facilitating positive developmental outcomes for athletes. In particular, the replicable curriculum provided here (in Table 1) is suggested for use by researchers and coaching educators as a basis for future coach training initiatives that 
share the aim of positive youth development. Further, coach transformational leadership behaviour is associated with other important drivers of positive youth development including intrinsic motivation, positive interpersonal connections and sustained effort towards goal attainment [16-18, 43]. However, causal evidence is needed as a first step.

The impact of perceived increases in coach transformational leadership on the positive developmental experiences of athletes must also take into account other salient variables. Firstly, it is still relatively unknown how actual coaching behaviour is related to positive youth development when compared to perceived coaching behaviour [39]. In a mediational model presented by Smoll and Smith [11] coach training interventions can provide changes to actual coaching behaviours. However, actual coaching behaviours are mediated by athlete perceptions of coaching behaviours when it comes to athlete outcomes. Further, it must be acknowledged that coaching practice occurs within a wider context. According to Bronfenbrenner's [44] ecological systems model of development the coach represents one microsystem amongst other microsystems such parents and peers. Each of these will have an influence of the positive development of young athletes. Research shows that while the influence on the coach remains relatively high across athletes aged from 10-18 years of age, the role of parents is strongest in the younger ranges while the influence of peers is strongest in the later adolescent years [45]. Further, the interrelations among microsystems may also play an influential role in athlete development. For example, the relationship between parent and coach will have an impact upon young athletes [46]. According to Bronfenbrenner [44], macrosystems such as the sporting culture and club values are also influential in facilitating positive development.

This research has several strengths. Firstly, this study has conducted "real world” research by collaborating with community sporting organisations to provide an indication of the effectiveness of the transformational leadership training program. This is an important 
and marked difference from 'efficacy’ studies that are undertaken in controlled conditions and are removed from the reality of coaching practice [47]. Further, the naturalistic comparison group utilised in this study afforded a sample size that is rarely achieved in research of this nature, thus providing power to the results and subsequent conclusions. In addition, the comparison group and pre-post design give sufficient reason to suggest that these results can serve to strengthen the evidence base which demonstrates an association between transformational leadership and positive youth development. However, there are also limitations that warrant mention. This study did not account for the number of years that coaches had spent with their athletes. This may be important because it is plausible that coaches who are in their second or subsequent year with the same athletes may indeed have already facilitated positive developmental gains in previous years. Thus, developmental experiences in subsequent years may be reduced. Further, the anonymous nature of responses that was imposed on this study dictated that it was impossible to follow participants from baseline to follow-up. Thus, it is uncertain how many of the potential sample provided measures over both seasons. This places strict limits on the strength of conclusions, and causal inferences are not possible. Thus, only significant differences have been reported here, without reference to "increases” or "decreases”. Future research should endeavor to follow individual athletes and coaches over time in order to make causal inferences. Lastly, the coaches in the comparison group did not receive any face-to-face time. Thus, in the sense that this was not strictly a control group, any differences between the groups may also be explained by the expectations of coaches in the intervention group, rather than the intervention itself.

\section{Conclusion.}

The transformational leadership training program was associated with higher rates of perceived transformational leadership behaviour at follow up when compared to baseline 
measures. Importantly, these increases were associated with significantly higher rates of selfreported developmental experiences of adolescent athletes. Coach training was associated with a predictability and reliability to athlete outcomes that was not evident in athletes of a comparison group. Transformational leadership may provide a theoretically sound foundation for coaching practice and education in the service of facilitating positive developmental outcomes for athletes, pending further longitudinal research with the ability to make causal inferences.

\section{References}

1. Benson, P.L., Scales, P.C., Hamilton, S.F. and Sesma Jr., A., Positive Youth Development: Theory, Research and Applications, in: Damon, W. and Lerner, R.M., eds., Handbook of Child Psychology: Theoretical Models of Human Development, 6th edn, Wiley and Sons, New York, 2006, 894-941.

2. Damon, W., What is Positive Youth Development?, The Annals of the American Academy of Political and Social Science, 2004, 591, 13-24.

3. Larson, R.W., Positive Development in a Disorderly World, Journal of Research on Adolescence, 2011, 21, 317-334.

4. $\quad$ Bruner, M.W., Hall. J. and Côté J., Influence of Sport Type and Interdependence on the Developmental Experiences of Youth Male Athletes, European Journal of Sport Science, 2011, 11, 131-142.

5. Hansen, D.M., Larson, R.W. and Dworkin, J.B., What Adolescents Learn in Organized Youth Activities: A Survey of Self-Reported Developmental Experiences, Journal of Research on Adolescence, 2003, 13, 25-55.

6. Broh, P.L., Linking Extracurricular Programming to Academic Achievement: Who Benefits and Why?, Sociology of Education, 2002, 75, 69-91.

7. Horn, T.S., Coaching Effectiveness in the Sport Domain, in: Horn, T.S., ed., Advances in Sport Psychology, Human Kinetics, Champaign, 2008, 239-268.

8. Weiss, M.R., 'Field of Dreams': Sport as a Context for Youth Development, Research Quarterly for Exercise and Sport, 2008, 79, 434-449.

9. Vella, S.A., Oades, L.G. and Crowe, T.P., The Relationship Between Coach Leadership, the Coach-Athlete Relationship, Team Success, and the Developmental Experiences of Young Athletes, Physical Education and Sport Pedagogy, In Press.

10. Fraser-Thomas, J.L., Côté, J. and Deakin, J. Youth Sport Programs: An Avenue to Foster Positive Youth Development, Physical Education and Sport Pedagogy, 2005, 10, 19-40.

11. Smoll, F.L. and Smith, R.E., Conducting Psychologically Oriented Coach Training Programs: A Social-Cognitive Approach, in: Williams, J.M., ed., Applied Sport Psychology: Personal Growth to Peak Performance, McGraw-Hill Publishers, Boston, MA., 392-415.

12. Côté, J. and Gilbert, W., An Integrative Definition of Coaching Effectiveness and Expertise, International Journal of Sports Science and Coaching, 2009, 4, 307-323. 
13. Jelicic, H., Bobek, D.L., Phelps, E., Lerner, R.M. and Lerner, J.V., Using Positive Youth Development to Predict Contribution and Risk Behaviors in Early Adolescence: Findings from the First Two Waves of the 4-H Study of Positive Youth Development, International Journal of Behavioral Development, 2007, 31, 263-273.

14. Vella, S.A., Oades, L.G. and Crowe, T.P., The Role of the Coach in Facilitating Positive Youth Development: Moving from Theory to Practice, Journal of Applied Sport Psychology, 2011, 23, 33-48.

15. Price, M.S. and Weiss, M.R., Relationships Among Coach Leadership, Peer Leadership, and Adolescent Athletes' Psychosocial and Team Outcomes: A Test of Transformational Leadership Theory, Journal of Applied Sport Psychology, In Press.

16. Charbonneau, D., Barling, J. and Kelloway, E.K., Transformational Leadership and Sports Performance: The Mediating Role of Intrinsic Motivation, Journal of Applied Sport Psychology, 2001, 31, 1521-1534.

17. Callow, N., Smith, M.J., Hardy, L., Arthur, C.A. and Hardy, J. Measurement of Transformational Leadership and its Relationship with Team Cohesion and Performance Level, Journal of Applied Sport Psychology, 2009, 21, 395-412.

18. Rowold, J., Transformational and Transactional Leadership in Martial Arts, Journal of Applied Sport Psychology, 2006, 18, 312-325.

19. Vallee, C.N. and Bloom, G.A., Building a Successful University Sporting Program: Key and Common Elements of Expert Coaches, Journal of Applied Sport Psychology 2005, 17, 179-196.

20. Avolio, B.J. and Bass, B.M., Developing Potential Across a Full Range of Leadership: Cases on Transactional and Transformational Leadership, Lawrence Erlbaum Associates, Mahwah, NJ, 2002.

21. Vella, S.A., Oades, L.G., and Crowe, T.P., Validation of the Differentiated Transformational Leadership Inventory as a Measure of Coach Leadership in Youth Soccer, The Sport Psychologist, 2012, 26, 203-224.

22. Larson, R.W., Toward a Psychology of Positive Youth Development, American Psychologist, 2000, 55, 170-183.

23. Vella, S.A., Oades, L.G. and Crowe, T.P., The Application of Coach Leadership Models to Coaching Practice: Current State and Future Directions, International Journal of Sports Science and Coaching, 2010, 5, 425-434.

24. Becker, A.J., It's Not What They Do, It's How They Do It: Athlete Experiences of Great Coaching, International Journal of Sports Science and Coaching, 2009, 4, 93114.

25. Smith, R.E., Smoll, F.L. and Cumming, S.P., Effects of a Motivational Climate Intervention for Coaches on Children's Sport Performance Anxiety, Journal of Sport \& Exercise Psychology, 2007, 29, 39-59.

26. Smith R.E., Smoll, F.L. and Barnett, N.P., Reduction of Children's Sport Performance Anxiety Through Social Support and Stress-Reduction Training for Coaches, Journal of Applied Developmental Psychology, 1995, 16, 125-142.

27. Coatsworth, D.E. and Conroy, J.D., Enhancing the Self-Esteem of Youth Swimmers Through Coach Training: Gender and Age Effects, Psychology of Sport and Exercise, 2006, 7, 173-192.

28. Guba, E.G., Criteria for Assessing the Trustworthiness of Naturalistic Inquiries, Educational Technology Research and Development, 1981, 29, 75-91.

29. Grant, A.M. and Wall, T.D., The Neglected Science and Art of QuasiExperimentation: Why-to, When-to, and How-to Advice for Organizational Researchers, Organizational Research Methods, 2009, 12, 653-686. 
30. Cook, T.D. and Campbell, D.T., Quasi-experimentation: Design and Analysis Issues for Field Settings, Rand McNally Publishing Company, Chicago, IL, 1979.

31. MacDonald, D.J., Côté, J., Eys, M. and Deakin, J., Psychometric Properties of the Youth Experience Survey with Young Athletes, Psychology of Sport and Exercise, 2012, 13, 332-340.

32. Smoll, F.L. and Smith, R.E., Mastery Approach to Coaching: A Leadership Guide for Youth Sports, Authors, Washington, 2009.

33. Smith, R.E. and Smoll, F.L., Coach-Mediated Team Building in Youth Sports. Journal of Applied Sport Psychology, 1997, 9, 114-132.

34. Smoll, F.L., Smith, R.E., Barnett, N.P. and Everett, J.J., Enhancement of Children's Self-Esteem through Social Support Training for Youth Sport Coaches, Journal of Applied Psychology, 1993, 78, 602-610.

35. Wilson, C. Best practice in Performance Coaching : A Handbook for Leaders, Coaches, HR Professionals, and Organizations, Kogan Page, London, UK, 2007.

36. Tabachnick, B.G. and Fidell, L.S., Using Multivariate Statistics, 5th edn, Pearson Education, Boston, MA, 2007.

37. Vella, S.A., Crowe, T.P. and Oades, L.G., Increasing the Effectiveness of Formal Coach Education: Evidence of a Parallel Process, International Journal of Sports Science and Coaching, In Press.

38. Petitpas, A.J., Cornelius, A.E., Van Raalte, J.L., and Jones, T., A Framework for Planning Youth Sport Programs that Foster Psychosocial Development, The Sport Psychologist, 2005, 19, 63-80.

39. Conroy, D.E. and Coatsworth, J.D., Coach Training as a Strategy for Promoting Youth Social Development, The Sport Psychologist, 2006, 20, 128-144.

40. MacDonald, D.J., Côté, J. and Deakin, J., The Impact of Informal Coach Training on the Personal Development of Youth Sport Athletes, International Journal of Sports Science and Coaching, 2010, 5, 363-372.

41. Cushion, C.J., Armour, K.M. and Jones, R.L., Coach Education and Continuing Professional Development: Experience and Learning to Coach, Quest, 2003, 55, 215230.

42. Vargas-Tonsing, T.M., Coaches’ Preference for Continuing Coaching Education, International Journal of Sport Science and Coaching, 2007, 2, 25-35.

43. Arthur, C.A., Woodman, T., Ong, C.W., Hardy, L. and Ntoumanis, N., The Role of Athlete Narcissism in Moderating the Relationship Between Coaches' Transformational Leader Behaviours and Athlete Motivation, Journal of Sport and Exercise Psychology, 2011, 33, 3-19.

44. Bronfenbrenner, U., The ecology of Human Development: Experiments by Nature and Design, Harvard University Press, Cambridge, MA., 1979.

45. Chan, D.K., Lonsdale, C. and Fung, H.H., Influences of Coaches, Parents and Peers on the Motivational Patterns of Child and Adolescent Athletes, Scandinavian Journal of Medicine and Science in Sports, 2012, 22, 558-568.

46. Smoll, F.L., Cumming, S.P. and Smith, R.E., Enhancing Coach-Parent Relationships in Youth Sports: Increasing Harmony and Minimizing Hassle, International Journal of Sports Science and Coaching, 2011, 6, 13-26.

47. Gartlehner, G., Hansen, R.A., Nissman, D., Lohr, K.N. and Carey, T.S., A Simple and Valid Tool Distinguished Efficacy from Effectiveness Studies, Journal of Clinical Epidemiology, 2006, 59, 1040-1058. 